\title{
Neonatal Sympathoadrenal Response to Acute Hypoxia: Impairment after Experimental Intrauterine Growth Retardation ${ }^{1}$
}

\author{
PHILIP W. SHAUL, ${ }^{2}$ CHUNG-JA M. CHA, AND WILLIAM OH \\ Brown University Program in Medicine, Department of Pediatrics, Women and Infants' Hospital of Rhode \\ Island, Providence, Rhode Island 02905
}

\begin{abstract}
Sympathoadrenal system function may be altered following intrauterine growth retardation (IUGR). We tested the hypothesis that the growth-retarded newborn rat pup has increased basal sympathoadrenal activity under normoxic conditions and a blunted sympathoadrenal response to acute hypoxia. IUGR was established by uterine artery ligation on $\mathbf{d} 18$ of gestation in Sprague-Dawley rats. Growth-retarded pups were chosen as those whose birth wt was more than $2 \times$ SD below the mean birth wt of control pups delivered to sham-operated dams. At $24 \pm$ $12 \mathrm{~h}$ of age cardiac sympathetic neuronal activity (CSNA) was determined by ${ }^{3} \mathrm{H}$-norepinephrine tracer and $\alpha$-methyltyrosine techniques. Adrenal medullary catecholamine synthesis (CAT SYN) was measured by ${ }^{14} \mathrm{C}$-tyrosine precursor methods, and adrenal catecholamine release (CAT REL) was determined using $\alpha$-methyl-tyrosine. IUGR and control pups were studied over a 120 -min period of normoxia or hypoxia $\left(\mathrm{FiO}_{2}=0.09\right)$. Under normoxic conditions, the IUGR pups had increased CSNA and increased adrenal CAT SYN and CAT REL compared to controls. Adrenal CAT REL in normoxic IUGR pups was selective for epinephrine. In response to acute hypoxia, control pups had increased CSNA and increased adrenal CAT SYN and CAT REL compared to normoxic controls, with the proportion of norepinephrine and epinephrine released mimicking the ratio of the two amines in the adrenal. In contrast, in hypoxic IUGR pups CSNA and adrenal CAT SYN did not increase, and norepinephrine alone was released from the adrenal medulla. It is speculated that IUGR in the rat may lead to an acceleration of cardiac sympathetic innervation and premature establishment of neural regulation of adrenomedullary function, resulting in impaired sympathoadrenal responses to acute stresses such as hypoxia. Compromised sympathoadrenal system function in the IUGR fetus or newborn may contribute to the pathogenesis of the perinatal morbidities and the increased perinatal mortality known to occur in this high risk population. (Pediatr Res 25:466-472, 1989)
\end{abstract}

Received July 1, 1988; accepted December 6, 1988.

Reprints William Oh, M.D., Department of Pediatrics, Women and Infants Hospital of Rhode Island, 101 Dudley Street, Providence, RI 02905.

Supported in part by Training Grant No. 5 IT32AM07187-11, National Institutes of Child Health and Human Development.

${ }^{1}$ Presented in part at the Annual Meeting of The Society for Pediatric Research, May 1986.

${ }^{2}$ Present address: Department of Pediatrics, University of Texas Southwestern Medical Center at Dallas, 5323 Harry Hines Blvd., Dallas, TX 75235.
Abbreviations

IUGR, intrauterine growth retardation

$\mathrm{NE}$, norepinephrine

$\alpha \mathrm{MT}, \alpha$-methyl-tyrosine

EPI, epinephrine

IP, intraperitoneal

Clinical experience indicates that the fetus or neonate with IUGR is highly susceptible to hypoxia in the perinatal period. Intrapartum asphyxia is 10 times more common and the risk of perinatal mortality is eight times greater in the IUGR infant than in the non-IUGR infant $(1,2)$. When fetal heart rate tracings have been examined comparing IUGR infants to those whose birth wt is appropriate for gestational age, the IUGR group has been found to have a higher incidence of decelerations and greater lactic acidosis when abnormal tracings are present (3-5). The sympathoadrenal system, composed of the sympathetic nervous system and catecholamine-producing chromaffin tissue such as the adrenal medulla, plays an important role in the response of the fetus or neonate to hypoxia (6-8). Previous studies of IUGR suggest that the activity of the sympathoadrenal system may be altered in growth retardation. IUGR fetal lamb studies and human investigations in which amniotic fluid catecholamine concentrations were measured during IUGR pregnancies suggest that the IUGR fetus may have increased sympathoadrenal tone in utero (6-9). In addition, one fetal lamb study suggests that the IUGR fetus may have a diminished plasma catecholamine response to acute hypoxia compared to controls (8). An impaired response to acute stresses such as hypoxia may contribute to the pathogenesis of the perinatal morbidities and the increased perinatal mortality known to occur in this high risk population.

The purpose of the present study was to determine the activity of the components of the sympathoadrenal system in the IUGR newborn under basal normoxic conditions and in response to acute hypoxia in an established rat model of uteroplacental insufficiency. Methods were employed to assess separately the function of the sympathetic nervous system and the adrenal medulla. We tested the hypothesis that the IUGR newborn rat has increased basal sympathoadrenal activity under normoxic conditions and an impaired sympathoadrenal response to acute hypoxia.

\section{MATERIALS AND METHODS}

Animal preparation. The rat was chosen as the animal model because the development of the sympathoadrenal system of the 
rat has been studied extensively (10-12) and because the rat has been successfully employed as a subject for experimental growth retardation using the uterine artery ligation technique first described by Wiggelsworth, or a modification of that technique $(13-15)$. Slotkin and others have shown that after normal rat pregnancies the sympathetic innervation of the newborn heart may be incomplete until the latter half of the 1st wk of life, and adrenomedullary catecholamine release is not neurogenically mediated until approximately the same postnatal age (10-11). However, after maternal stress during the last $5 \mathrm{~d}$ of gestation, the sympathetic innervation of the heart and the adrenomedullary response to stress are intact in 1-day-old rat pups (16-18). In the present study, the evaluation of sympathoadrenal activity was performed at $24 \pm 12 \mathrm{~h}$ of age in an effort to study the rat pups soon after birth, but not during the period of immediate postnatal adaptation and stabilization (19). As the establishment of the experimental group required maternal surgery late in gestation and as such surgery may affect fetal sympathoadrenal development, the control group was chosen to be pups born to similarly operated dams differing from experimental dams only in that they did not undergo the uterine artery ligation to produce uteroplacental insufficiency.

Time-dated pregnant Sprague-Dawley rats were used (Taconic Farms, Germantown, NY). The morning after mating overnight, when the females were sperm positive, was denoted as $\mathrm{d} l$ of gestation. The dams were housed individually in wood-chip bedded plastic cages at $23^{\circ} \mathrm{C}$ with light-dark cycles of $12 \mathrm{~h}$ each They were given free access to a stock diet and tap water. The dams were then randomized to enter the experimental group or the control group before surgery on $\mathrm{d} 18$ of gestation. In the experimental group, a low midline laparotomy incision was made under ether anesthesia, the uterus was exposed, and 3-0 silk ligatures were placed bilaterally around the uterine arteries at the cervical ends. The uterus was then replaced and the laparotomy incision was closed. The sham surgical procedure for the control dams was identical to that of the experimental group except that the ligation of the uterine arteries was not performed. The dams were then allowed to deliver spontaneously on d 22 or 23 of gestation.

The newborn pups were weighed within $6 \mathrm{~h}$ of the time of birth. IUGR pups were selected to be those pups born to ligated dams whose birth wt was more than $2 \times$ SD below the mean birth wt of the control pups. The pups were housed with their mothers until the time of study.

Experimental design. Sympathoadrenal system function was determined in two separate sets of studies. The first set of studies involved the determination of plasma catecholamine concentrations and cardiac sympathetic neuron activity by measurement of NE turnover in the neurons using $\left[{ }^{3} \mathrm{H}\right]-\mathrm{NE}$ as the tracer substance. The methods used were modifications of techniques previously established in developing and adult rats by Landsberg and others (20-24). At 15 min before the beginning of the study period, the pups received $500 \mathrm{nCi}$ of $\left[{ }^{3} \mathrm{H}\right]-\mathrm{NE}, \mathrm{I}\left[(\mathrm{N})-7,8-{ }^{3} \mathrm{H}\right] \mathrm{NE}$ (18.8 Ci/mmol, New England Nuclear/DuPont, Boston, MA), administered IP. Preliminary studies indicated that the $\left[{ }^{3} \mathrm{H}\right]-\mathrm{NE}$ content of cardiac tissue reached equilibrium within $15 \mathrm{~min}$ of administration. The pups were then placed in a wood chipbedded, covered clear plastic chamber with the air temperature maintained at $29^{\circ} \mathrm{C}$ by a convective heat source. The pups were studied for up to $120 \mathrm{~min}$ under normoxic conditions receiving room air or under hypoxic conditions receiving a gas mixture with an $\mathrm{FiO}_{2}$ of 0.09 , $\mathrm{FiCO}_{2}$ of 0.025 , balanced with nitrogen, administered into the chamber at a flow rate of 2 liters $/ \mathrm{min}$. The $\mathrm{FiO}_{2}$ was monitored continuously with an IMI 3300 oxygen analyzer (Datamedic, Inc., Sharon, MA). At preselected times during the study period $(0,15,30,60$, and $120 \mathrm{~min})$ the pups were killed by rapid decapitation. Mixed arterial and venous trunk blood was immediately obtained, centrifuged and serum stored at $-70^{\circ} \mathrm{C}$, and the heart was harvested, weighed and stored also at $-70^{\circ} \mathrm{C}$ until biochemical analyses were performed. Pups from the same litter were studied throughout the 120 -min period In a separate group of animals, trunk blood gases were measured using a Corning 175 blood gas analyzer (Corning Scientific, Medford, MA) to confirm the establishment of hypoxic conditions.

The second set of studies involved the evaluation of adrenal medulla catecholamine synthesis and release. The rate of catecholamine synthesis was determined by measurement of the rate of synthesis of ${ }^{14} \mathrm{C}$-labeled adrenal catecholamines over the study period after the administration of tracer doses of ${ }^{14} \mathrm{C}$-tyrosine precursor. The methods used were modifications of techniques previously established to measure in vivo catecholamine synthesis in the adrenal gland and in other tissues in the rat $(25-29)$. At the onset of the study period the rat pups received $3 \mu \mathrm{Ci} / \mathrm{g}$ birth wt of uniformly labeled L-tyrosine $-{ }^{14} \mathrm{C}(525 \mathrm{mCi} / \mathrm{mmol}$, New England Nuclear) by IP injection. They were then placed in the study chamber under either normoxic or hypoxic conditions for $120 \mathrm{~min}$ as described above. At the end of the study period, the rat pups were killed by rapid decapitation, and the adrenal glands were harvested for the determination of ${ }^{14} \mathrm{C}$-labeled catecholamine content.

Adrenal medulla catecholamine release was determined by measurement of the decline in adrenal catecholamine content over the study period following pretreatment with $\alpha \mathrm{MT}$, a potent inhibitor of the rate-limiting step of catecholamine synthesis. In addition to providing a means of assessing adrenal medulla catecholamine release, $\alpha \mathrm{MT}$ pretreatment is also an alternative method of evaluation of cardiac sympathetic neuron activity by measurement of cardiac NE release. The methods used were similar to those previously established by Gordon and others $(25-27,30)$. At the onset of the study period, the rat pups received $\alpha \mathrm{MT}, 400 \mu \mathrm{g} / \mathrm{g}$ birth wt, or an equivalent vol of vehicle (normal saline) by IP injection. Studies by Udenfriend et al. (26) have shown that such a dose of $\alpha$ MT causes virtually $100 \%$ reduction of conversion of ${ }^{14} \mathrm{C}$-tyrosine to catecholamines in the adrenal gland. Preliminary dose-response studies verified that this dose effectively inhibited adrenal catecholamine synthesis and was well tolerated by the animals. As in the adrenal catecholamine synthesis studies, the rat pups were then placed in the study chamber under either normoxic or hypoxic conditions for 120 min. At the end of the study period, the rat pups were killed by rapid decapitation; the adrenal glands and hearts were harvested, and catecholamine content was determined. Rat pups were also killed at time 0 to allow for the measurement of adrenal and cardiac catecholamine content at baseline.

Methodology. Plasma, cardiac, and adrenal NE and EPI contents were determined by high performance liquid chromatography with electrochemical detection (LC-4A Electrochemical Detector, Bioanalytical Systems, Inc., West Layfayette, IN). The catecholamines were isolated from the plasma and tissues after deproteinization by absorption onto alumina at $\mathrm{pH} 8.6$ followed by elution with $0.2-\mathrm{N}$ perchloric acid (31). Chromatography was performed using a revision of the methods of Hjemdahl et al. (32). Dihydroxybenzylamine was used as the internal standard and the recovery of catecholamines was $70-80 \%$. The lower limits of sensitivity were approximately $20 \mathrm{pg}$ injected for NE and $30 \mathrm{pg}$ injected for EPI. For NE the intraassay and interassay coefficients of variation were $6.6 \%$ and $12.0 \%$, respectively, and for EPI they were $6.7 \%$ and $10.0 \%$, respectively. Cardiac $\left[{ }^{3} \mathrm{H}\right]-$ $\mathrm{NE}$ content and adrenal ${ }^{14} \mathrm{C}$-labeled catecholamine content were determined by liquid scintillation spectrometry using a Beta Trac 6895 Liquid Scintillation System (Tn Analytic, Inc., Elk Grove Village, IL). Counting efficiencies for ${ }^{3} \mathrm{H}$ and ${ }^{14} \mathrm{C}$ were $40-43 \%$ and $81 \%$, respectively. The minute size and gelatinous consistency of the adrenal gland in 1-d-old rat pups precluded accurate dissection and weighing, or separation of cortex from medulla. As such, adrenal endogenous catecholamine content and adrenal catecholamine synthesis are expressed per adrenal gland (17). 
Data analysis and statistical methods. Cardiac NE turnover analysis with $\left[{ }^{3} \mathrm{H}\right]$-NE is based upon two observations in developing and adult rats. The first is that catecholamines in the rat heart are confined to the sympathetic terminal axons and that $\mathrm{NE}$ is the predominant amine (33). Secondly, the sp act of labeled $\mathrm{NE}$ in the heart declines as a single exponential obeying first order kinetics. After administration, tracer doses of $\left[{ }^{3} \mathrm{H}\right]-\mathrm{NE}$ rapidly equilibrate with endogenous NE within the cardiac sympathetic nerve endings. The labeled NE is then released along with endogenous NE in response to sympathetic stimulation. The slope of a semilogarithmic plot of the decline in NE specific activity versus time equals the fractional NE turnover rate. The fractional NE turnover rate correlates with the degree of cardiac sympathetic neuronal activity as assessed by other methods such as the measurement of neuron electrical potentials $(20-22,24)$. The fractional NE turnover rates were calculated from data obtained during the study period by the method of least squares. The results were compared between study groups by analysis of covariance $(24,34)$.

Single comparisons of parameters between groups were performed by unpaired Student $t$ tests. Multiple comparisons between study groups or over time were performed by analysis of variance with post hoc testing using the Bonferroni correction $(35,36)$. A $p$ value $<0.05$ was considered to be statistically significant.

\section{RESULTS}

Populations studied. In the first set of studies examining plasma catecholamine concentrations and cardiac ${ }^{3} \mathrm{H}-\mathrm{NE}$ turnover 10 dams were sham-operated and 38 underwent uterine artery ligation. At $6 \mathrm{~h}$ of postnatal life $74 \%$ of control fetuses and $34 \%$ of fetuses in the experimental group were alive. Of control pups, $4 \%$, and of experimental group pups $62 \%$, met the criteria for IUGR. Of control pups, 99\% survived from 6-24 h of life, yielding 74 control pups alive at the time of study. Of experimental group pups, $89 \%$ survived from $6-24$ h of life ( $87 \%$ for IUGR $v s .92 \%$ for non-IUGR, $p>0.05$ ), yielding 69 IUGR pups alive at the time of study. The mean birth wt of the control pups was $6.18 \pm 0.44 \mathrm{~g}(\overline{\mathrm{X}} \pm \mathrm{SD})$. The mean birth wt of the IUGR pups was $4.46 \pm 0.50 \mathrm{~g}$, well below the birth wt of the control pups $(p<0.001)$ as dictated by study design. In the second set of studies, comparable birth wt were obtained. The mean birth wt for the adrenal medulla catecholamine synthesis experiments were $6.17 \pm 0.41(n=17)$ vs. $4.50 \pm 0.53 \mathrm{~g}(n=$ $15, p<0.001)$, and for the adrenal catecholamine release experiments they were $6.17 \pm 0.45(n=36)$ vs. $4.52 \pm 0.45 \mathrm{~g}(n=39$, $p<0.001$ ) for control and IUGR pups, respectively.

Blood gases. Additional control and IUGR pups were placed under identical study conditions to confirm the establishment of hypoxia. At $24 \pm 12 \mathrm{~h}$ of life mixed arterial-venous trunk blood was obtained after $120 \mathrm{~min}$ in the study chamber in either room air (normoxia) or $\mathrm{FiO}_{2}=0.09$ (hypoxia). Results are shown in Table 1. Control pup trunk blood $\mathrm{PO}_{2}$ fell from $47.5 \pm 5.7 \mathrm{~mm}$ $\mathrm{Hg}$ under normoxic conditions to $28.5 \pm 2.0 \mathrm{~mm} \mathrm{Hg}$ under hypoxic conditions $(p<0.005)$, and IUGR pup trunk blood $\mathrm{PO}_{2}$ fell from $52.3 \pm 9.2 \mathrm{~mm} \mathrm{Hg}$ to $30.6 \pm 4.8 \mathrm{~mm} \mathrm{Hg}(p<0.005)$. There were no differences in $\mathrm{PO}_{2}$ between control and IUGR pups under similar conditions. In both control and IUGR groups, the pups had a mild respiratory alkalosis when they received the hypoxia gas mixture, despite the administration of an $\mathrm{FiCO}_{2}$ of 0.025 to counteract hypocarbia due to hyperventilation.

Plasma catecholamine concentrations. At the onset of the study period the plasma EPI concentration was similar in control and IUGR pups (Fig. 1). In response to hypoxia, the control pups had an increase in plasma EPI that was significantly greater than the plasma EPI for IUGR pups at 5 and $60 \mathrm{~min}$ of hypoxia. The data at $5 \mathrm{~min}$ of hypoxia were obtained on a separate group of pups who were studied post hoc to ensure that a rise in plasma EPI prior to $15 \mathrm{~min}$ of hypoxia had not been overlooked. By the end of the period of hypoxia, the plasma EPI concentration in controls was back near baseline and similar to IUGR values. Both the control and IUGR groups had no change in plasma EPI during the 2-h study period under normoxic conditions (data not shown).

At baseline the plasma NE concentration was also similar in control and IUGR pups (Fig. 2). In response to hypoxia the control pups had a more than 2-fold increase in plasma NE at 60-min; the elevation in NE did not occur in the hypoxic IUGR pups. As occurred with EPI, the plasma NE concentration in controls at 120 min of hypoxia was back to baseline and similar to IUGR values. Both the control and IUGR groups had no change in plasma NE during the 2-h study period under normoxic conditions (data not shown).

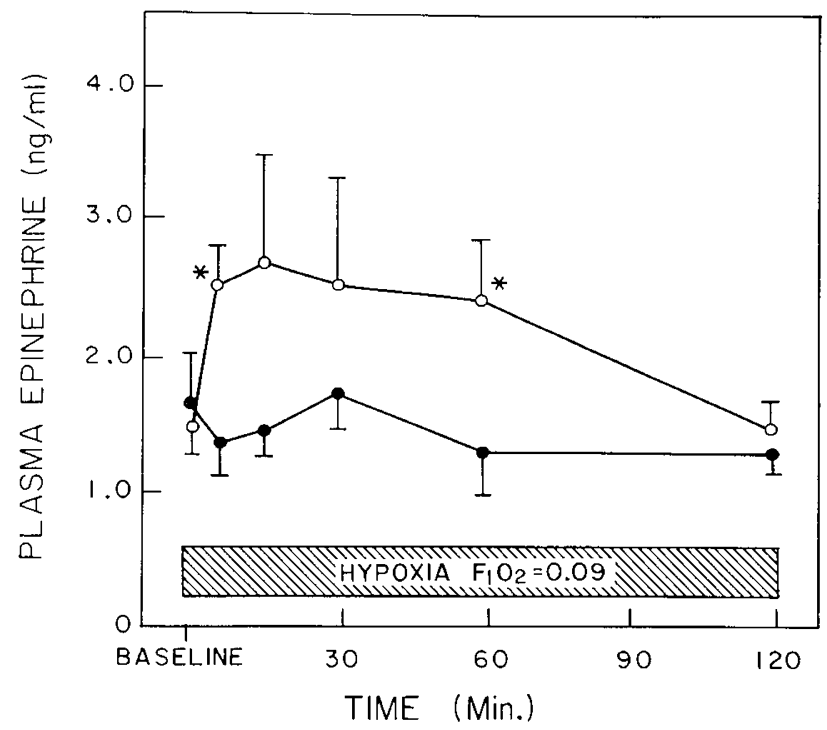

Fig. 1. Plasma EPI response to acute hypoxia in control and IUGR rat pups. Values for control pups are represented by the open circles and values for IUGR pups are represented by the closed circles. Each point with error bars represents the mean \pm SEM of determinations on six pups. ${ }^{*} p<0.05$ vs. IUGR.

Table 1. Trunk blood gases obtained on control and IUGR rat pups after 120 minutes of normoxic or hypoxic conditions*

\begin{tabular}{lccccc}
\hline & \multicolumn{2}{c}{ Control } & & \multicolumn{2}{c}{ IUGR } \\
\cline { 2 - 3 } \cline { 5 - 6 } & Normoxia & Hypoxia & & Normoxia & Hypoxia \\
\hline $\mathrm{pH}$ & $7.44 \pm 0.03$ & $7.48 \pm 0.04 \dagger$ & $7.46 \pm 0.04$ & $7.50 \pm 0.05$ \\
$\mathrm{PCO}_{2}(\mathrm{~mm} \mathrm{Hg})$ & $42.9 \pm 3.9$ & $35.2 \pm 2.0 \dagger$ & & $42.6 \pm 1.8$ & $35.1 \pm 4.7 \dagger$ \\
$\mathrm{PO}_{2}(\mathrm{~mm} \mathrm{Hg})$ & $47.5 \pm 5.7$ & $28.5 \pm 2.0 \dagger$ & $52.3 \pm 9.2$ & $30.6 \pm 4.8 \dagger$ \\
Base excess (mEq/liter) & $4.8 \pm 2.4$ & $3.7 \pm 2.4$ & $6.2 \pm 3.2$ & $5.3 \pm 2.9$ \\
$(n)$ & $(7)$ & $(7)$ & $(6)$ & $(5)$ & \\
\hline
\end{tabular}

${ }^{*}$ Control and IUGR rat pups were placed under identical study conditions to confirm the establishment of hypoxia. Values represent the mean $\pm \mathrm{SD}$. The values in parentheses represent the number of pups sampled.

$\dagger p<0.05$ vs. normoxia, same group. 


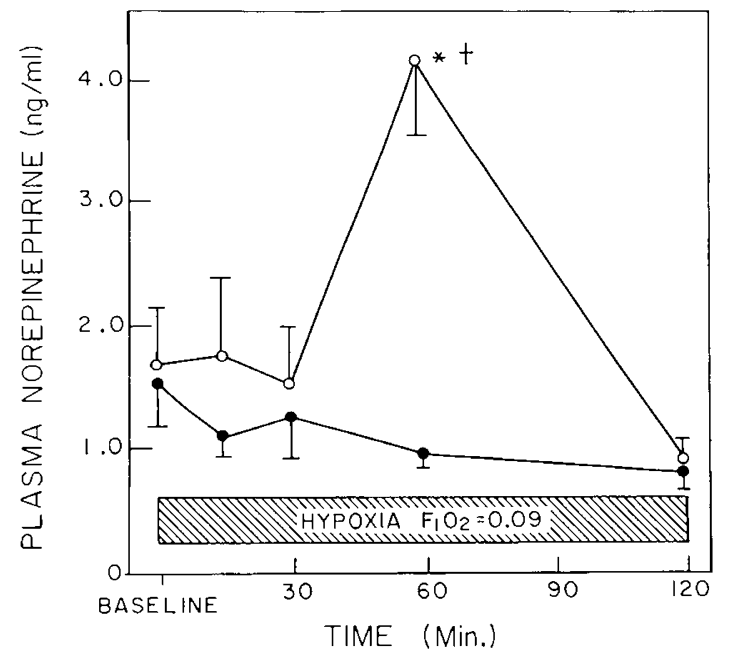

Fig. 2. Plasma NE response to acute hypoxia in control and IUGR rat pups. Values for control pups are represented by the open circles and values for IUGR pups are represented by the closed circles. Each point with error bars represents the mean \pm SEM of determinations on six pups. ${ }^{*} p<0.05$ vs. IUGR; $\uparrow p<0.05$ vs. baseline.
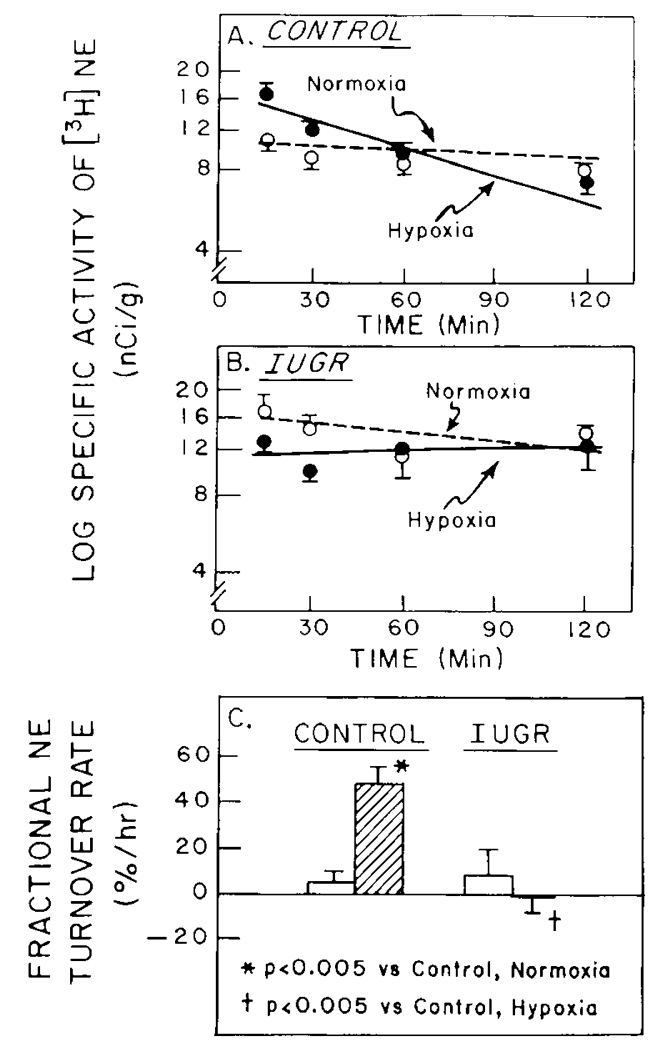

Fig. 3. Cardiac sympathetic neuron activity determined by measurement of ${ }^{3} \mathrm{H}-\mathrm{NE}$ turnover in control and IUGR rat pups under normoxic and hypoxic conditions. Upper panel: ${ }^{3} \mathrm{H}-\mathrm{NE}$ turnover in control pups. Least squares plots of the log of the sp act of ${ }^{3} \mathrm{H}-\mathrm{NE}$ in the cardiac tissue $v s$. time are shown. The mean \pm SEM of values for six normoxic pups are represented by the open circles and error bars. The mean \pm SEM of values for six hypoxic pups are represented by the closed circles and error bars. Middle panel: ${ }^{3} \mathrm{H}-\mathrm{NE}$ turnover in IUGR pups. Lower panel: Fractional NE turnover rates for control and IUGR pups under normoxic (open bars) or hypoxic (cross-hatched bars) conditions. The fractional $\mathrm{NE}$ turnover rates are the slopes of the semilogarithmic plots shown in the upper and middle panels. The bars and the error bars represent the mean $\pm \mathrm{SD}$. The turnover rates are compared between groups by analysis of covariance. ${ }^{*} p<0.005$ vs. control; normoxia, $\nmid p<0.005 v s$. control, hypoxia.
Cardiac sympathetic neuron activity. The results of the determination of cardiac sympathetic neuron activity by measurement of $\left[{ }^{3} \mathrm{H}\right]$-NE turnover are shown in Figure 3 . In the control pups (Fig. 3, upper panel) there was an increase in cardiac $\left[{ }^{3} \mathrm{H}\right]-\mathrm{NE}$ turnover in response to hypoxia compared to normoxia. In contrast, in the IUGR pups (Fig. 3, middle panel) there was no change in cardiac $\left[{ }^{3} \mathrm{H}\right]$-NE turnover during hypoxic compared to normoxic conditions. During normoxia, control pups and IUGR pups had similar fractional NE turnover rates (Fig. 3, lower panel). During hypoxia, the control pups had a more than 10 -fold increase in fractional NE turnover rate. This response was absent in hypoxic IUGR pups. Turnover rates for control normoxic, IUGR normoxic and IUGR hypoxic groups were not significantly different from 0 .

The results of the assessment of cardiac sympathetic neuron activity by measurement of endogenous cardiac NE turnover following $\alpha \mathrm{MT}$ pretreatment are shown in Figure 4. At baseline the endogenous cardiac NE content was similar in control and IUGR pups. After pretreatment with $\alpha \mathrm{MT}$, endogenous NE content declined by $37 \%$ over 120 min under normoxic conditions in control pups. In the normoxic $\alpha$ MT-treated IUGR pups there was a $59 \%$ decline in endogenous NE content over 120 min, greatly exceeding the decline observed in control pups. This indicated that under normoxic conditions, cardiac sympathetic neuron activity as assessed by this method was greater in IUGR pups than in control pups. After pretreatment with $\alpha \mathrm{MT}$, endogenous NE content declined an additional $18 \%$ in hypoxic compared to normoxic control pups, supporting the finding in the $\left[{ }^{3} \mathrm{H}\right]-\mathrm{NE}$ studies that the control pups had an increase in cardiac sympathetic neuron activity in response to hypoxia. In contrast, in the IUGR pups there was no additional decline in endogenous NE content under hypoxic conditions compared to normoxic conditions. This is consistent with the results for hypoxic IUGR pups in the $\left[{ }^{3} \mathrm{H}\right]$-NE studies. Cardiac endogenous NE content was also measured in control and IUGR pups after $2 \mathrm{~h}$ of normoxic or hypoxic conditions after receiving vehicle alone. In

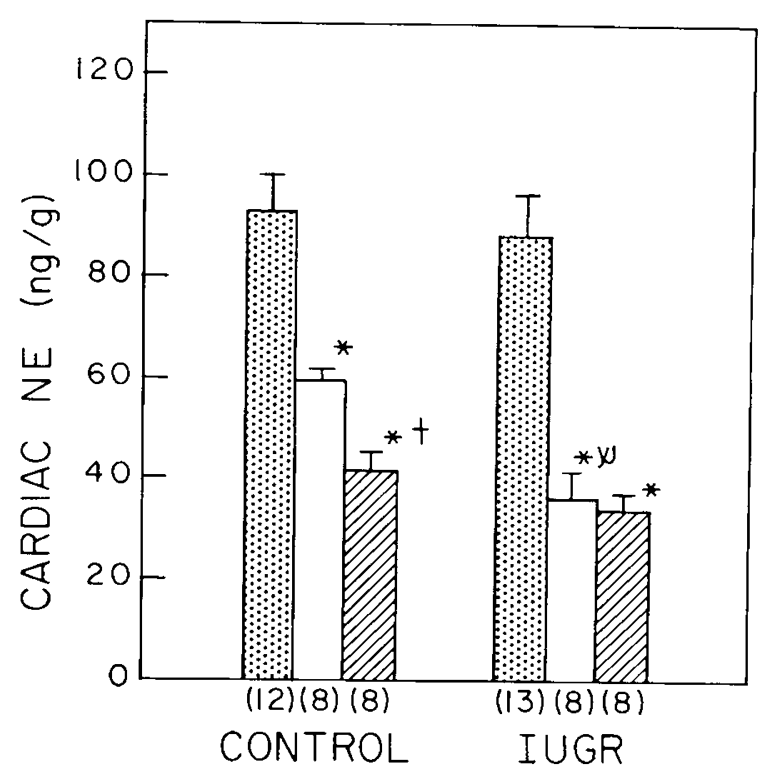

Fig. 4. Cardiac sympathetic neuron activity determined by measurement of endogenous cardiac NE turnover after $\alpha$-methyl-tyrosine pretreatment. The bars and the error bars represent the mean \pm SEM of values for the number of animals studied as noted in the parentheses. Baseline cardiac endogenous norepinephrine content is shown by the stippled bars. Cardiac NE content after $\alpha$-methyl-tyrosine pretreatment and $120 \mathrm{~min}$ in normoxic conditions is shown by the open bars. Cardiac $\mathrm{NE}$ content after $\alpha$-methyl-tyrosine pretreatment and $120 \mathrm{~min}$ in hypoxic conditions is shown by the cross-hatched bars. ${ }^{*} p<0.005$ vs. baseline, $\dagger p<0.005$ vs. normoxia, $\psi p<0.005 v s$. control. 
these animals cardiac NE content was unchanged compared to baseline values (data not shown).

Adrenal catecholamine synthesis and release. The results of the adrenal catecholamine synthesis studies using ${ }^{14} \mathrm{C}$-tyrosine are shown in Figure 5. Under normoxic conditions adrenal catecholamine synthesis in control pups was $30 \%$ less than in IUGR pups. In response to hypoxia the control pups had a $38 \%$ increase in adrenal catecholamine synthesis. In contrast, there was no increase in adrenal catecholamine synthesis in the IUGR pups in response to hypoxia.

The results of adrenal catecholamine release experiments are shown in Figure 6. Total adrenal catecholamine content represents the sum of NE and EPI content. Other catecholamines such as dopamine were not included because NE and EPI accounted for more than $95 \%$ of all adrenal catecholamines. Baseline total catecholamine, NE, and EPI contents were similar in control and IUGR pups. After pretreatment with $\alpha \mathrm{MT}$ under normoxic conditions, adrenal NE and EPI content did not

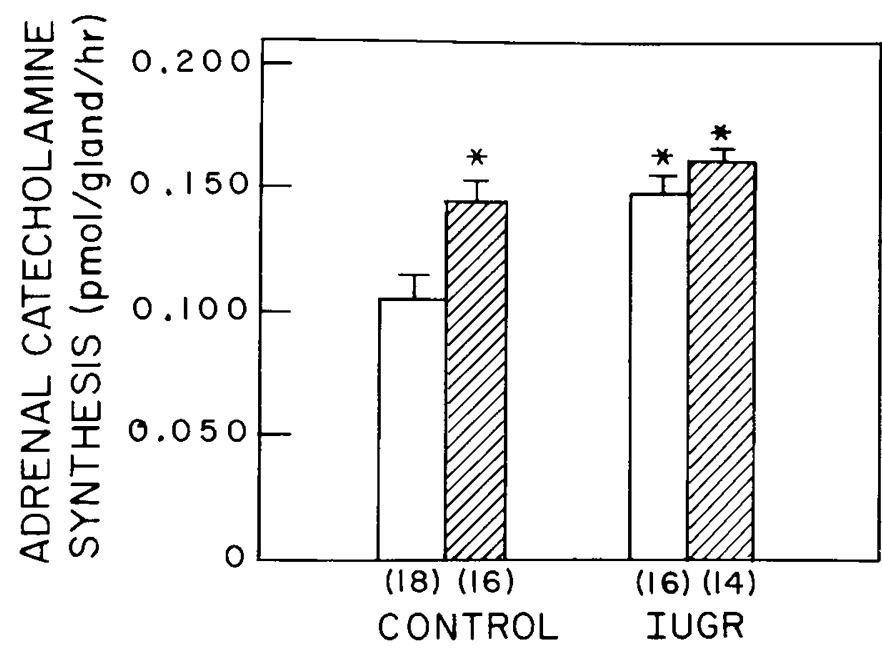

Fig. 5. Adrenal catecholamine synthesis in control and IUGR rat pups under normoxic and hypoxic conditions. The bars and the error bars represent the mean \pm SEM of values for the number of animals studied as noted in parentheses. Adrenal catecholamine synthesis under normoxic conditions is shown by the open bars. Synthesis under hypoxic conditions is shown by the cross-hatched bars. ${ }^{*} p<0.05$ vs. control, normoxia. change in control pups, indicating that basal adrenal catecholamine release was not detectable. In normoxic IUGR pups NE content did not change, but EPI content was decreased by $44 \%$ from baseline. Thus, under normoxic conditions the IUGR pups had greater adrenal catecholamine release than controls, and the release was selectively EPI. After pretreatment with $\alpha \mathrm{MT}$ under hypoxic conditions, both adrenal NE and EPI content declined in control pups. Catecholamine release was not selective, in that the percentage of total catecholamines remaining as EPI after hypoxia $(74 \%)$ was similar to the percentage as EPI at baseline $(75 \%)$. The decline in adrenal NE and EPI content with hypoxia in control pups is consistent with the observed elevations in plasma NE and EPI concentrations in response to hypoxia in the first set of studies. In contrast, in the IUGR pups under hypoxic conditions there was a decline in adrenal NE content, but there was no additional release of EPI compared to normoxic conditions. The release of adrenal NE in hypoxic IUGR pups was not evident in the first set of studies, in that there was no detectable increase in plasma NE concentration. Adrenal catecholamine content was also measured in control and IUGR pups after $2 \mathrm{~h}$ of normoxic or hypoxic conditions after receiving vehicle alone. In these animals, adrenal NE and EPI content were similar to baseline values (data not shown).

\section{DISCUSSION}

In the present studies, cardiac sympathetic neuronal activity and adrenal medullary catecholamine synthesis and release were successfully determined in vivo under normoxic and hypoxic conditions in an established model of IUGR. The control group selected was optimal in that it differed from the experimental group only regarding the absence or presence of uteroplacental insufficiency late in gestation. The results support the hypothesis tested and reveal that IUGR may lead to dramatic alterations in sympathoadrenal system function in the newborn. Under normoxic conditions, the IUGR pups had increased cardiac sympathetic neuronal activity and increased adrenal medullary catecholamine synthesis and EPI release compared to controls. In response to acute hypoxia, the control pups had increased sympathetic neuronal activity and increased adrenal catecholamine synthesis and NE and EP release compared to normoxic controls. In contrast, in the IUGR pups the cardiac sympathetic neuronal response and the adrenal medullary EPI response to acute hypoxia were blunted.

The results for the control group were similar to findings in previous studies of the sympathoadrenal system of the rat. The

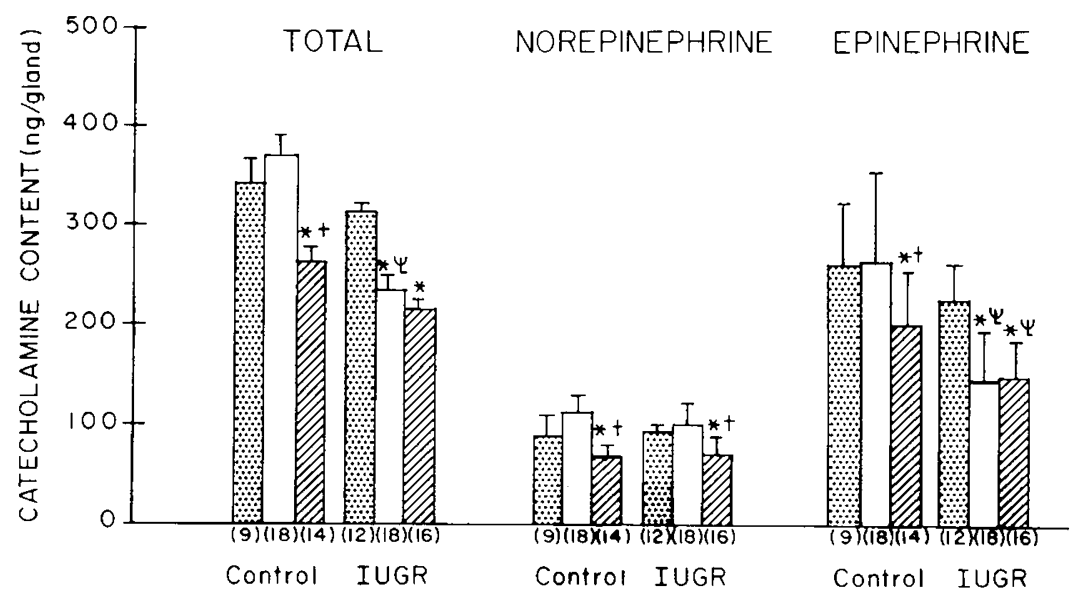

Fig. 6. Assessment of adrenal catecholamine release by measurement of remaining catecholamine content following blockade of new synthesis with $\alpha$-methyl-tyrosine. Total catecholamine content is the sum of NE and EPI content. The bars and the error bars represent the mean \pm SEM of valucs obtained on the number of animals studied as noted in the parentheses. Baseline adrenal total catecholamine, NE, and EPI content are shown by the stippled bars. Adrenal catecholamine content after $\alpha$-methyl-tyrosine pretreatment and 120 min in normoxic conditions is shown by the open bars. Catecholamine content after $\alpha$-methyl-tyrosine pretreatment and $120 \mathrm{~min}$ in hypoxic conditions is shown by the cross-hatched bars. ${ }^{*} p<0.05$ $v s$. baseline, $\nmid p<0.05 v s$. normoxia, $\psi p<0.05 v s$. control. 
plasma catecholamine concentrations for normoxic control pups were similar to those reported by Cuezva et al. (19) and BenJonathan (37). In the $\left[{ }^{3} \mathrm{H}\right]-\mathrm{NE}$ turnover studies of cardiac sympathetic neuronal activity, the mean fractional NE turnover rate for control pups under normoxic conditions was $4.6 \% / \mathrm{h}$, and this was similar to observations made by Johnson et al. (24) in older rats, where the range was 3 to $4 \% / \mathrm{h}$. No previous data are available regarding the NE turnover rate in newborn rats. The results for baseline endogenous cardiac and adrenal catecholamine content in control pups were similar to values reported by Iverson et al. (22) and Seidler and Slotkin (17).

The results of the studies of cardiac sympathetic innervation suggest that IUGR may affect the development of the cardiacsympathetic axis. As mentioned previously, after a normal pregnancy the sympathetic innervation of the newborn rat heart is not complete until the latter half of the 1st wk of life. However, it has been shown that with maternal stress, maternal drug addiction, and such neonatal conditions as experimental hyperthyroidism, this process can be greatly accelerated (10). The detectable basal cardiac sympathetic neuron activity in normoxic control pups and the observed increase in activity in response to acute hypoxia indicate that cardiac sympathetic innervation was intact by $24 \mathrm{~h}$ of postnatal age in our model. This may have been due to the stress of maternal surgery or other conditions present in our studies. The enhanced cardiac sympathetic neuron activity in normoxic IUGR pups, compared to normoxic controls, suggests that growth retardation may have resulted in even greater acceleration of the maturation of cardiac sympathetic innervation than that due to the study design alone. Additionally, the blunted cardiac sympathetic neuron response to acute hypoxia in the IUGR pups may indicate that the precocious appearance of cardiac sympathetic neurotransmission is neither beneficial nor even innocuous to the IUGR pup. It is possible that accelerated innervation in the IUGR pup may lead to both short-term and long-term alterations in the ultrastructure and function of the cardiac sympathetic-axis, as has been observed with accelerated innervation in experimental neonatal hyperthyroidism (10).

In addition to having had potential effects on cardiac sympathetic innervation, IUGR also may have resulted in altered adrenomedullary development. The normal ontogeny of adrenomedullary function in the rat occurs along a time course which is similar to that of cardiac sympathetic innervation. Surges of adrenomedullary activity in response to stress occur in the normal rat fetus and in the newborn at birth despite the absence of splanchnic control of the adrenal medulla. Splanchnic innervation then appears towards the end of the $1 \mathrm{st}$ wk postnatally, and it becomes mature by $10 \mathrm{~d}$ of age. The immature "nonneurogenic" response, which consists of adrenal NE and EPI release exactly duplicating their ratio in the immature gland, disappears as neural connections develop. The mature neurogenic secretion is characterized by selective release of either amine, depending upon the excitation of specific populations of spinal neurons ( 11 , $18,38)$. In the present study, the control pups had no detectable adrenal NE or EPI release under normoxic conditions, and catecholamine release in response to acute hypoxia was not selective, suggesting that it may have been nonneurogenic. In contrast, in the IUGR pups catecholamine release under normoxic conditions was exclusively EPI, and additional release under hypoxic conditions was exclusively NE. These observations may indicate that the IUGR pups had prematurely intact splanchnic nerve regulation of adrenomedullary function at 24 $\mathrm{h}$ of age, with different populations of spinal neurons being excited under normoxic and hypoxic conditions. In the IUGR pups, there was no increase in EPI release in response to hypoxic versus normoxic conditions, and this blunted response may have been due to the accelerated onset of splanchnic nerve competence. It has been found, in general, that conditions that accelerate the development of splanchnic nerve regulation of the rat adrenal medulla lead to premature loss of the nonneurogenic response mechanisms and loss of their protective effect regarding the survival of neonatal hypoxia (18).

Thus, in the present study IUGR newborn rat pups had increased basal sympathoadrenal activity under normoxic conditions and an impaired sympathoadrenal response to acute hypoxia compared to control pups. It is speculated that IUGR in the rat may lead to accelerated maturation of both the neuronal and adrenomedullary components of the sympathoadrenal system, resulting in an impaired ability of the IUGR newborn pup to respond to acute stresses such as hypoxia. Compromised sympathoadrenal responses to acute stress may contribute to the pathogenesis of the perinatal morbidities and the increased perinatal mortality associated with intrauterine growth retardation.

Acknowledgments. We are indebted to Ms. Nancy L. Gelardi and Ms. Joan Boylan for their skilled technical assistance. We are very grateful to Ms. Marilyn Dixon for preparing this manuscript.

\section{REFERENCES}

1. Cassady G 1981 The small-for-date infant. In: Avery GB (ed) Neonatalogy: Pathophysiology and Management of the Newborn, JB Lippincott CO, Philadelphia, pp 262-286

2. Cetrulo CL, Freeman R 1977 Bioelectric evaluation in intrauterine growth retardation. Clin Obstet Gynecol 20:979-989

3. Lin C, Moawad AH, Rosenow PJ, River P 1980 Acid-base characteristics of fetuses with intrauterine growth retardation during labor and delivery. Am J Obstet Gynecol 137:553-559

4. Odendall H 1979 Fetal heart rate patterns in patients with intrauterine growth retardation. Obstet Gynecol 48:187-190

5. Low JA, Pancham SR, Worthington D 1976 Fetal heart deceleration patterns in relation to asphyxia and weight-gestational age percentile of the fetus. Obstet Gynecol 47:14-20

6. Lagercrantz H, Sjoquist B, Bremme K, Lunell N, Somell C 1980 Catecholamine metabolites in amniotic fluid as indicators of intrauterine stress. Am J Obstet Gynecol 136:1067-1070

7. Llanos AJ, Green JR, Creasy RK, Rudolph AM 1980 Increased heart rate response to parasympathetic and beta adrenergic blockade in growth-retarded fetal lambs. Am J Obstet Gynecol 136:808-813

8. Jones CT, Robinson JS 1983 Studies on experimental growth retardation in sheep: plasma catecholamines in fetuses with small placenta. J Dev Physio 5:77-87

9. Divers WA, Wilkes MM, Babaknia A, Hill LM, Quilligan EJ, Yen SSC 198 Amniotic fluid catecholamines and metabolites in intrauterine growth retardation. Am J Obstet Gynecol 141:608-610

10. Slotkin TA 1986 Endocrine control of synaptic development in the sympathetic nervous system: the cardiac-sympathetic axis. In: Gootman PM (ed) Developmental Neurobiology of the Autonomic Nervous System. Humana Press. Clifton, NJ, pp 97-133

11. Slotkin TA 1986 Development of the sympathoadrenal axis. In: Gootman PM (ed) Developmental Neurobiology of the Autonomic Nervous System. Humana Press, Clifton, NJ, pp 69-96

2. Phillippe M 1983 Fetal catecholamines. Am J Obstet Gynecol 146:840-855

13. Wigglesworth JS 1964 Experimental growth retardation in the foetal rat. J Path Bact 88:1-13

14. Evans MI, Mukherjee AB, Schulman JD 1983 Animal models of intrauterine growth retardation. Obstet Gynecol Surv 38:183-192

15. Kollee LAA, Nonnens LAH, Trijbels JMF, Veerkamp JH, Janssen AJM 1979 Experimental intrauterine growth retardation in the rat: evaluation of the Wigglesworth model. Early Hum Dev 3:295-300

16. Smith PC, Mills E 1983 Abnormal development of blood pressure and growth in rats exposed to perinatal injection stress. Life Sci 32:2497-2501

17. Seidler FJ, Slotkin TA 1985 Adrenomedullary function in the neonatal rat responses to acute hypoxia. J Physiol (Lond) 358:1-16

18. Slotkin TA, Seidler FJ 1988 Adrenomedullary catecholamine release in the fetus and newborn: secretory mechanisms and their role in stress and survival. J Dev Physiol 10:1-16

19. Cuezva JM, Burkett ES, Kerr DS, Rodman HM, Patel MS 1982 The newborn of diabetic rat: I. Hormonal and metabolic changes in the postnatal period. Pediatr Res 16:632-637

20. Landsberg L, Young JB 1978 Fasting, feeding and regulation of the sympathetic nervous system. N Engl J Med 298:1295-1301

21. Neff NH, Tozer TN, Hammer W, Costa E, Brodie BB 1968 Application of steady-state kinetics to the uptake and decline of ${ }^{3} \mathrm{H}-\mathrm{NE}$ in the rat heart. Pharmacol Exp Ther 160:48-52

22. Iverson LL, DeChamplain J, Glowinski J, Axelrod J 1967 Uptake, storage and metabolism of norepinephrine in tissues of the developing rat. J Pharmacol Exp Ther 157:509-516

23. Glowinski J, Axelrod J, Kopin IJ, Wurtman RJ 1964 Physiological disposition of ${ }^{3} \mathrm{H}$-norepinephrine in the developing rat. J Pharmacol Exp Ther 146:48- 
53

24. Johnson TS, Young JB, Landsberg L 1983 Sympathoadrenal responses to acute and chronic hypoxia in the rat. J Clin Invest 71:1263-1272

25. Gordon R, Spector S, Sjoerdsma R, Udenfriend S 1966 Increased synthesis of norepinephrine and epinephrine in the intact rat during exercise and exponorepinephrine and epinephrine in the intact rat
sure to cold. J Pharmacol Exp Ther 153:440-447

26. Udenfriend S, Zaltzman-Nirenberg P, Gordon R, Spector S 1966 Evaluation of the biochemical effects produced in vivo by inhibitors of the three enzymes involved in norepinephrine biosynthesis. Mol Pharmacol 2:95-105

27. Nahas GG, Steinsland OS 1968 Increased rate of catecholamine synthesis during respiratory acidosis. Respir Physiol 5:108-117

28. Gordon R, Reid JVO, Sjoerdsma A, Udenfriend S 1966 Increased synthesis of norepinephrine in the rat heart on electrical stimulation of the stellate ganglia. Mol Pharmacol 2:606-613

29. Sedvall G, Kopin IJ 1967 Acceleration of norepinephrine synthesis in the rat submaxillary gland in vivo during sympathetic nerve stimulation. Life Sci 6:45-51

30. Steinsland OS, Passo SS, Nahas GG 1970 Biphasic effect of hypoxia on adrenal catecholamine content. Am J Physiol 218:995-998

31. Landsberg L, Berardino MB, Silva P 1975 Metabolism of ${ }^{3} \mathrm{H}$-L-dopa by the rat gut in vivo-evidence for glucuronide conjugation. Biochem Pharmaco 24:1167-1174

32. Hjemdahl P, Daleskog M, Kahan $\Upsilon 1979$ Determination of plasma catecholamines by high performance liquid chromatography with electrochemical detection: comparison with a radioenzymatic method. Life Sci 25:131-138

33. McLean MR, Goldberg PB, Roberts J 1983 An ultrastructural study of the effects of age on sympathetic innervation and atrial tissue in the rat. $J$ Mo Cell Cardiol 15:75-92

34. Snedecor GW, Cochran WG 1980 Statistical Methods. Iowa State University Press, Ames, lowa, pp 385-388

35. Snedecor GW, Cochran WG 1980 Statistical Methods. Iowa State University Press, Ames, lowa, pp 215-237, 255-273

36. Wallenstein S, Zacker CI, Fleiss JL 1980 Some statistical methods useful in circulation research. Cir Res 47:1-9

37. Ben-Jonathan N 1978 Plasma catecholamines in fetal and neonatal rats. Life Sci 23:39-44

38. Lau C, Ross LL, Whitmore WL, Slotkin TA 1987 Regulation of adrenal chromaffin cell development by the central monoaminergic system: differential control of norepinephrine and epinephrine levels and secretory responses. Neuroscience 22:1067-1075 